\title{
Professor readaptado: a precarização do trabalho docente e 0 adoecimento
}

\author{
Marilda Gonçalves Dias Facci' ${ }^{1}$, https://orcid.org/0000-0001-7443-490X \\ Sonia da Cunha Urt², https://orcid.org/0000-0002-0309-3498 \\ Ana Teresa Fernandes Barros' ${ }^{1}$, https://orcid.org/0000-0002-1453-9539
}

\begin{abstract}
Resumo
Hoje nos deparamos com vários professores que estão adoecendo e por isso sendo readaptados. Com essa perspectiva, objetivamos neste artigo discutir a relação estabelecida entre a precarização do trabalho e o adoecimento do professor readaptado tendo como fundamento os pressupostos da Psicologia Histórico-Cultural. Para a discussão da temática, discorreremos sobre as relações do trabalho e, na sequência, trataremos sobre a formação da personalidade e adoecimento, com respaldo nos estudos de A. N. Leontiev. Ilustraremos o artigo com dados de entrevistas efetivadas com 20 professores readaptados, da educação básica. Como resultados, observamos que as exigências que são postas ao trabalhador na atualidade, entre eles o professor, têm provocado estranhamento em relação à atividade docente, uma ruptura entre sentido e significado na prática profissional e, como consequência, o adoecimento. Concluindo, entendemos ser necessário trabalhar em prol da emancipação do professor, a fim de possibilitar o desenvolvimento máximo de suas potencialidades.
\end{abstract}

Palavras-chave: Trabalho docente; sofrimento; Psicologia Histórico-Cultural.

\section{Readapted teacher: precariousness of teaching and illness}

\begin{abstract}
Today we are faced with several teachers who are falling ill and therefore being readapted. With this perspective, we aim in this article to discuss the established relationship between the precariousness of work and the illness of the readapted teacher, based on the assumptions of Historical-Cultural Psychology. For the discussion of the subject, we will discuss the labor relations and, afterwards, we will deal with the formation of personality and illness, with support in the studies of A. Leontiev. We will illustrate the article with data from interviews conducted with 20 readapted teachers of basic education. As a result, we observe that the demands that are placed on the worker at the present time, among them the teacher, have caused estrangement in relation to the teaching activity, a rupture between meaning and meaning in professional practice and, as a consequence, illness. In conclusion, we believe that it is necessary to work towards the emancipation of the teacher, in order to enable the maximum development of his potentialities.
\end{abstract}

Keywords: Teaching work; suffering; Historical-Cultural Psychology.

\section{Professor readaptado: la precarizacion de La labor docente y el enfermarse}

\section{Resumen}

Hoy día nos deparamos con múltiples profesores que se están enfermando y por eso siendo readaptados. Con esta perspectiva, nuestro objetivo en este artículo fue discutir sobre la relación establecida entre la precarización de la labor y el enfermarse del profesor readaptado, se tuvo como fundamento los presupuestos dela Psicología Histórico-Cultural. Para la discusión de la temática, descorreremos sobre las relaciones de la labor y, en la secuencia, trataremos sobre la formación de la personalidad y el enfermarse, con respaldo en los estudios de A. N. Leontiev. llustraremos el artículo con datos de entrevistas realizadas con 20 profesores readaptados, de la educación básica. Como resultados, observamos que las exigencias que son puestas al trabajador en la actualidad, entre ellos el profesor, ha provocado extrañamiento en relación a la actividad docente, una ruptura entre sentido y significado en la práctica profesional y, como consecuencia, el enfermarse. Concluyendo, entendemos ser necesario trabajar en beneficio de la emancipación del profesor, a fin de posibilitar el desarrollo máximo de sus potencialidades.

Palabras clave: Trabajo docente; sufrimiento; Psicología Histórico-Cultural.

1 Universidade Estadual de Maringá - Maringá - PR - Brasil; marildafacci@gmail.com; anateresafb@gmail.com

2 Universidade Federal de Mato Grosso do Sul - Mato Gorro do Sul - MS - Brasil; sonia.urt@gmail.com 


\section{Introdução}

Os professores estão adoecendo. Com o intuito de desvendar esse fenômeno, nosso objetivo neste artigo é discutir a relação estabelecida entre a precarização do trabalho e o adoecimento do professor readaptado, tendo como fundamentos os pressupostos da Psicologia Histórico-Cultural. Ilustraremos o artigo com dados de entrevistas efetivadas com 20 professores readaptados da educação Básica do Norte do Estado do Paraná.

Gasparini, Barreto e Assunção (2005), em pesquisa sobre o adoecimento, analisaram um documento relativo aos afastamentos do trabalho de funcionários da Secretaria Municipal de Educação de Belo Horizonte, de abril de 2001 a maio de 2003, e constataram que nesse período os transtornos psíquicos constavam como ocupando o primeiro lugar entre os diagnósticos que provocaram os afastamentos (15\%). Em segundo lugar os autores observaram que estão as doenças do aparelho respiratório $(12 \%)$ e, em terceiro, as doenças do sistema osteomuscular e do tecido conjuntivo (11\%). Silva (2011) também constatou que no Estado de São Paulo, no primeiro semestre de 2010, o número de licenças médicas concedidas aos professores por transtornos psíquicos correspondeu a $70 \%$ de todas as solicitações feitas em 2009. Quando essas licenças tornam-se consecutivas, muitos professores são colocados na categoria de professor readaptado.

A readaptação é o "o provimento do funcionário em cargo mais compatível com a sua capacidade física ou intelectual e vocação, podendo ser realizada ex-ofício ou a pedido do interessado" (Lei n. 6174/70, 1970, p. 20). O professor readaptado continua trabalhando na escola, mas não ministra aulas e desempenha outra função. No Estado do Paraná, na instrução normativa n. 02/2007 - GRHS/SEED (Instrução normativa n. 02/2007, 2007), consta que esses profissionais podem desenvolver atividades na coordenação pedagógica, na coordenação de laboratório, na coordenação de informática e no auxílio às atividades desenvolvidas pela direção, no tocante à vinculação com a comunidade.

No Estado de São Paulo, de acordo com Antunes (2014), no primeiro quadrimestre de 2013 a rede pública de ensino contabilizou 14.340 professores readaptados por motivo de doença. No período de 2011 a 2013 a taxa de crescimento de professores readaptados foi de $24,9 \%$ no Estado.

Com esses estudos mencionados, vimos que é necessário ainda investigações sobre o adoecimento. Na primeira parte do artigo discorreremos sobre a precarização do trabalho e, na sequência, discutiremos a formação da personalidade e adoecimento. No decorrer da exposição desses temas vamos apresentar algumas informações de entrevista realizada com um grupo de 20 professores de escolas públicas da Educação Básica do Estado do Paraná que estão readaptados.

Consideramos necessário informar que esses dados dizem respeito a um recorte de uma pesquisa maior vinculada ao pós-doutoramento de uma das autoras. O projeto de pesquisa foi aprovado pelo Comitê de Ética em Pesquisa com Seres Humanos de uma universidade do Estado do Paraná. O procedimento metodológico adotado para a coleta das informações foi a entrevista semi-estruturada, utilizando um roteiro composto de dados de identificação e questões sobre as relações de trabalho e adoecimento. As entrevistas foram realizadas nas escolas onde os professores ministravam aulas.

Quanto à caracterização dos participantes da investigação, o grupo foi constituído por 18 mulheres e dois homens, com faixa etária de 40 a 69 anos, com a maior concentração de professores entre 55-59 anos (35\%), seguido de 50-44 anos (20\%). O tempo de formação em maior percentagem ficou entre $26-30$ anos (30\%) e 16-20 anos (20\%). Quanto ao tempo de docência, 40\% dos professores ministram aulas entre 26-30 anos. Somente três professores têm menos de 16 anos de docência, e entre eles, um tem três anos. O tempo de readaptação se concentrou entre dois e dez anos, totalizando $70 \%$ (40\% entre $02-05$ e $30 \%$ entre 6-10 anos). Os professores foram nominados como S1, S2, e assim, sucessivamente, para garantir o seu anonimato. Traremos respostas dos professores referentes às condições e satisfação no trabalho e como essas condições interferem na atividade (considerando os pressupostos de Leontiev) que executam na escola, buscando exemplificar como as condições de trabalho estão provocando adoecimento.

\section{O processo de precarização do trabalho}

Os professores, considerados como trabalhadores, sofrem com a precarização do trabalho. Tumolo e Fontana (2008) afirmam que esses profissionais, tais como outras categorias, vivenciam o processo de proletarização de suas condições de trabalho, configurado como rebaixamento salarial, desqualificação da atividade realizada, desvalorização social da profissão, perda de controle do processo de trabaIho, por exemplo.

Para Marx e Engels (1996, p. 39) por meio do trabalho os homens transformam a natureza, produzem seus meios de vida, seus alimentos "...que permitam a satisfação das necessidades, a produção da própria vida material”. O homem, de acordo com Marx (1988, p. 202), "Atuando assim sobre a natureza externa e modificando-a, ao mesmo tempo modifica sua própria natureza". Ao mesmo tempo, também constrói a totalidade social, conforme analisa Lessa (2012).

Markus (2015) afirma, no processo histórico, que a criação e a utilização dos instrumentos levaram à superação da vida dirigida somente pelo aspecto biológico, provocaram o domínio sobre a natureza e o domínio sobre si mesmo. Aquilo que deu e dá possibilidades de humanização, também criou, na sociedade capitalista, o poder de destruição do homem, pois hoje o que predomina é o trabalho abstrato - "... uma atividade social assalariada, alienada do capital" (Lessa, 2012, p. 26). Nessa situação, o sentido ontológico do trabalho não é vivenciado por muitos trabalhadores.

No capitalismo ocorre um estranhamento em relação ao trabalho. Antunes (2002) e Netto e Carvalho (2015), ba- 
seados em Marx, expõem quatro formas de estranhamentos. O primeiro é o estranhamento em relação à natureza, o seu objeto: quanto mais produz menos tem para consumir; estranhamento que ocorre entre o trabalhador e a objetivação do seu trabalho. O segundo ponto refere que o trabalhador também não se reconhece em sua atividade produtiva, com o ato de produção. Marx (2008) analisa que primeiramente o trabalho, na sociedade capitalista, “... aparece ao homem apenas como meio para a satisfação de uma carência, a necessidade de manutenção da existência física" (p. 84). Como afirmam Netto e Carvalho (2015), o trabalho é um meio para conseguir dinheiro e adquirir aquelas mercadorias necessárias para a sua subsistência. O trabalhador possui apenas a sua força de trabalho, pois outra classe é que detém os meios de produção, necessários à produção de mercadorias imprescindíveis para manter o homem vivo.Esse trabalho estranhado, de acordo com Marx (2008), produz, então, o terceiro estranhamento: o estranhamento do gênero humano. Ele não se reconhece, segundo Antunes (2002, p. 120), na sua “... relação entre 'vida do gênero' e 'vida individual'”. Cabe ao trabalhador se apropriar parcialmente daquilo que os homens, no percurso histórico, já produziram. Por fim, um quarto estranhamento, é do homem pelo próprio homem. Como afirma Marx (2008, p. 86), isto quer dizer que “... um homem está estranhado do outro, assim como cada um deles [está estranhado] da essência humana.".

Marx (2008, p. 82) afirma:

O trabalhador só se sente, por conseguinte e em primeiro lugar, junto a si [quando] fora do trabalho e fora de si [quando] no trabalho. Está em casa quando não trabalha e, quando trabalha, não está em casa. O seu trabalho não é, portanto, voluntário, mas forçado, trabalho obrigatório. O trabalho não é, por isso, a satisfação de uma carência, mas somente um meio para satisfazer necessidades fora dele. (Marx, 2008, p. 82 , grifos do autor).

Como analisa Marx (2008, p. 82), nesse processo o homem, ao produzir as mercadorias, acaba se tornando, ele próprio, uma mercadoria. Isso se deu e continua ocorrendo na atualidade, pois Marx e Engels (1996, p.29) enfatizam que “... cada nova fase da divisão do trabalho determina igualmente as relações dos indivíduos entre si, no que se refere ao material, ao instrumento e ao produto do trabaIho." Quanto mais avança a divisão do trabalho, quanto mais se põe em risco a supressão da propriedade privada, mais aprofunda o estranhamento dos trabalhadores e mais necessário se torna alterar as formas de gestão do trabalho.

Quando retomamos a história observamos que várias formas de submetimento do homem ao trabalho ocorreram em épocas passadas, seja no modo de produção primitivo, no escravismo, no feudalismo, por exemplo. No início do século $X X$, já no capitalismo, o modo de organização do trabalho teve forte influência das ideias de Frederic Taylor (1856-1915),que previa uma maior organização do trabaIho nas fábricas, maior rigidez e controle da produção para eliminar falhas e erros, alocação do homem certo no lugar certo e precisão dos movimentos repetitivos realizados pelo trabalhador nas esteiras de montagem. Paralelamente à consolidação do Taylorismo, Henri Ford (1863-1947), desenvolveu um projeto de linha de montagem, fundamentado, segundo Heloani (2003), na tecnologia (mecanização) e nos princípios tayloristas, buscando aumentar os lucros.Antunes (2009, p. 43, grifos do autor), em relação aos dois modelos apresentados, analisa que o taylorismo/fordismo “... realizava uma expropriação intensificada do operário-massa, destituindo-o de qualquer participação na organização do processo de trabalho, que se resumia a uma atividade repetitiva e desprovida de sentido".

Nos anos 1960 as ações dos trabalhadores tornaram-se mais acirradas, conforme anuncia Antunes (2006) e estes começaram a questionar a sociabilidade do capital e o controle social da produção, gerando crise no sistema de produção. O fordismo perdura até 1973, mas já em 1960 começa a declinar. O modelo japonês de gestão, o toyotismo, se apresenta como a possibilidade de resolver, na superficialidade, as relações de trabalho. Inicia-se a implantação de uma política de trabalho flexível, com mudanças na organização deste, pois exigia-se, de acordo com Heloani e Capitão (2003) “... respostas rápidas por parte do capital". Nesse sistema de produção, Antunes $(2009,2011)$ pondera que além da flexibilização do trabalho - característica importante do Toyotismo - houve também a flexibilização do trabalhador. Passam-se a desenvolver as atividades com um mínimo de trabalhadores, amplia-se a necessidade de horas extras, de trabalhadores temporários, de trabalhadores parciais (integrados parcialmente às empresas), de subcontratados, terceirizados e os trabalhadores da "economia informal".

Essas mudanças “... afetaram a forma de ser da classe trabalhadora, tornando-a mais heterogênea, fragmentada e complexificada" (Antunes, 2011, p. 63, grifo do autor). Desemprego ampliado, rebaixamento de salário, desmonte da legislação trabalhista com perdas dos direitos que são resultados de lutas históricas dos trabalhadores, perda da força sindical, precarização exacerbada, terceirização, fazem parte do sistema de trabalho vivenciado desde meados do século $\mathrm{XX}$ e acabam trazendo sofrimento para o trabaIhador. Ocorre, de acordo com Antunes e Praun (2015, pp. 423-424) uma "... diminuição drástica das fronteiras entre atividade laboral e espaço da vida privada." O trabalhador tem, a todo custo, que cumprir metas estabelecidas pelos dirigentes. Essas metas, segundo Antunes e Praun (2015), se tornam um mecanismo disciplinador, no qual o próprio trabalhador controla seu comportamento na busca do aumento de produtividade; levam a um controle das faltas pelas equipes de trabalho; reduzem o tempo de repouso; promovem competição entre os trabalhadores e equipes, assim como aprofundam as experiências de acordos coletivos firmados pelos empregadores. A terceirização, por sua vez, promove a prática de contratos temporários para atender às demandas de mercado, provocando desestruturação da classe trabalhadora. $\mathrm{Na}$ escola isso é visível com os vários contratos temporários que produzem rotatividade de professores, entre outros pontos que interferem na prática pedagógica. 
Precarização e intensificação do trabalho passam a ordenar a forma de relação do homem com os campos de ação profissional. Tais transformações trazem para o trabaIhador, de acordo com Hirata (2002, p. 16), “... em primeiro lugar, danos múltiplos à saúde física e psíquica; em segundo lugar, aumento da distância entre assalariados e desempregados e, de modo mais amplo, entre os trabalhadores e aqueles que se encontram sem emprego".

A precarização, no caso da atividade do professor, incide juntamente com as reformas educacionais. Assunção e Oliveira (2009) afirmam que essas reformas propostas no Brasil, a partir de 1990, ocorrem coerentes com as reformas do Estado na forma de gestão pública, que busca uma descentralização administrativa e financeira, repassando obrigações e responsabilidades para as próprias escolas, trazendo como consequência: “... o financiamento per capita, a regularidade e ampliação dos exames nacionais de avaliação, maior flexibilidade curricular, a avaliação institucional e a participação da comunidade na gestão escolar" (Assunção \& Oliveira, 2009, p. 351). Eficácia, produtividade e excelência permeiam as relações de trabalho. O professor está cada vez mais extenuado pela intensificação do trabalho, ficando susceptível ao adoecimento, uma vez que tem que extrapolar os seus limites. Tal fato foi observado em nossa pesquisa, na qual oito professoras afirmaram que adoeceram em função do excesso de trabalho, da sobrecarga de trabalho, das cobranças, da preocupação em cumprir as tarefas.

Professores da educação básica são avaliados, constantemente, pelos índices de desempenho dos alunos, medidos pelos sistemas de avaliação como por exemplo, pelo Índice de Desenvolvimento da Educação Básica (Ideb) - que avalia o fluxo escolar e as médias de desempenho nas avaliações, que dá um ranking das melhores escolas. Desta forma, os próprios trabalhadores se autorregulam. As reformas educacionais e junto com elas os vários sistemas avaliativos têm causado danos à saúde dos professores e gestores. Três professoras entrevistadas mencionaram que o processo de avaliação adotado se constitui em ponto negativo no trabalho.

Nessa linha da precarização do trabalho dos professores, Sampaio e Marin (2004), igualmente, apresentam alguns elementos que estão presentes na atividade destes profissionais. Primeiramente, no que se refere à necessidade de escolaridade, a precarização ocorre no caso dos professores iniciantes sem experiência e sem poder trocar experiência com os mais antigos e no caso daqueles que têm experiência em trabalharem com conteúdos diversificados ao mesmo tempo e por anos seguidos. Outro ponto de precarização refere-se aos baixos salários recebidos. A terceira forma de precarização ocorre com relação às condições de trabalho: carga horária de trabalho e de ensino, tamanho das turmas e razão entre professor/alunos, rotatividade/itinerância dos professores pelas escolas e as questões sobre carreira no magistério.

Tais aspectos também foram relatados pelos professores entrevistados no Paraná, pois 14 docentes mencionaram que consideravam desagradável ou desprazeroso o trabalho que executam e citaram as condições de infraestrutura física e pedagógica das escolas, tais como falta de suporte técnico - pedagógico; estrutura física ruim; salas superlotadas, falta de equipamentos desportivos nas escolas, local com muito barulho; falta de material pedagógico; organização das aulas em 45 minutos cada e sistema de avaliação adotado na escola. Além disso, cinco professores mencionaram também as tarefas realizadas na atividade docente como ter que avaliar os alunos, preencher livros de chamada, cobranças realizadas ao professor para dar aulas diferentes; outros quatro também citaram as dificuldades relacionadas à falta de investimento dos governantes na educação.

Uma professora entrevistada retratou bem essa questão no seguinte depoimento:

... acho que o professor é muito cobrado. Ele tem que dar aula diferente, dinâmica, hoje com as mídias. Mas a gente não tem essas condições dentro da escola; a gente não tem um wi-fi que funcione, uma tv que funcione com pen drive, um multimídia que você chega lá com o seu computador e ele funcione. (S6)

Foi perguntado aos professores, também, o que dava prazer, satisfação no trabalho. Eles ponderam que era o contato com o aluno $\left(n=12^{1}\right)$, ensinar e dar aula $(n=9)$, a interação com os demais professores $(n=8)$, observar o desenvolvimento dos alunos e o progresso na vida posterior $(n=5)$, o interesse dos alunos $(n=2)$, o ambiente escolar $(n$ =1) e a mobilidade, por ser professor de educação física. Foi possível observar, agrupando aqueles que gostam do contato com o aluno e com demais professores, que as interações estabelecidas na escola são consideradas pontos positivos no trabalho. Em segundo lugar, também pudemos constatar que eles sentem prazer em ensinar e ver os alunos aprendendo. Quando interrogados sobre o nível de satisfação no trabalho, obtivemos os seguintes percentuais: $35 \%$ satisfeitos, $10 \%$ extremamente satisfeitos, $15 \%$ muito satisfeitos, ou seja, $60 \%$ estão satisfeitos.

Podemos analisar que embora haja uma finalidade clara, estabelecida, da função do professor, as condições de trabalho não possibilitam que aquilo que seria a essência da sua prática - ensinar - ocorra diante das condições objetivas apresentadas. Os problemas vão se avolumando, levando os professores ao adoecimento, pois todos os entrevistados apresentam algum problema de saúde, o que justifica o fato de estarem readaptados na função. Eles têm clareza da finalidade do trabalho, mas esse estranhamento presente nas relações de trabalho leva muito professores a não "se sentirem em casa" no trabalho, vendo na ocupação o impedimento da sua humanização, do desenvolvimento das suas potencialidades. Gostam dos alunos, ficam felizes quando eles aprendem, mas as condições de trabalho não

1 Nas questões abertas da entrevista utilizamos a frequência das respostas para a análise, considerando que o mesmo professor, em algumas situações, deu mais de uma resposta para as perguntas apresentadas. "n", portanto, significa o número de vezes que a resposta foi emitida. 
possibilitam que eles se vejam como fazendo parte do processo; são apenas apêndices.

Somente quatro professores (20\%) afirmaram que os motivos do adoecimento não estavam vinculados ao trabaIho, pois justificaram que problemas familiares, pessoais, levaram aos problemas de ordem psíquica, tais como separação, morte ou doença de algum membro da família. Ter que falar muito e em tom alto devido à indisciplina e as condições da escola levaram três docentes ao processo de readaptação por problemas de voz. Oito professores mencionaram as condições de trabalho como promotoras de adoecimento, conforme discutimos anteriormente. Três professores ainda relataram que a frustração por não conseguirem fazer o que haviam proposto, levando os alunos a aprenderem, também influenciou o adoecimento. Dois professores falam da indisciplina dos alunos e um menciona um roubo em sua casa por alunos da escola que contribuiu para o processo de depressão. Outro professor menciona as brigas políticas na escola e também um deles fala do descompromisso do governo com a educação como causa do sofrimento.

O professor sente que é alguém improdutivo, que não tem competência. $\mathrm{O}$ trabalho em sala de aula, as pressões postas, as cobranças, as dificuldades de lidar com o aluno são tão grandes, que ele incorpora a noção de incapacidade e adoece diante do trabalho que quer executar. Não é necessário que alguém fale que ele não está conseguindo realizar a tarefa proposta. Ele mesmo se sente ameaçado diante dos alunos, dos pais, não consegue lidar mais com o cotidiano, o que leva ao adoecimento.

Toda essa situação influencia a formação da sua personalidade, invade seus sentimentos e a forma de relacionar com outras pessoas e consigo mesmo. Interfere na sua subjetividade e sobre isso trataremos no próximo item.

\section{Atividade, formação da personalidade e adoecimento}

Uma categoria importante para a compreensão do psiquismo é a atividade. Martins e Eidt (2010) afirmam que a atividade tem como função produzir e reproduzir as condições necessárias para inserção do homem na sociedade. A criança, quando nasce, começa a estabelecer relação com os objetos e com outras pessoas. Essa relação ocorre por meio de uma atividade guia, como é o caso, por exemplo, da criança no período pré-escolar em que a atividade guia é o jogo de papéis, ou, no caso do adulto, o trabalho, a atividade profissional. Por meio do trabalho o homem se relaciona com a sociedade e pode desenvolver suas potencialidades. Não é isso o que sempre ocorre na sociedade capitalista, por conta da alienação, mas esta deveria ser uma possibilidade posta com o campo de atuação profissional.

A atividade possui uma estrutura geral composta de necessidade, motivo e ação. De acordo com Leontiev (1978a), a necessidade orienta e regula a atividade concreta do sujeito na realidade. O autor comenta que "Toda atividade do organismo está dirigida a satisfazer as necessidades na- quilo que lhes é indispensável para prolongar e desenvolver sua vida" (Leontiev, 1969, p. 341). O conceito de atividade está relacionado ao de motivo - aquilo que incita a ação. "Se denomina motivo da atividade aquilo que refletindo-se no cérebro do homem excita a atuar e dirige esta atuação a satisfazer uma necessidade determinada" (Leontiev, 1969, p. 346, grifos do autor). Este pode ser tanto de caráter material como ideal. Não existe atividade sem um motivo, embora este nem sempre seja conscientizado.

A atividade é composta de uma cadeia de ações e estas, por sua vez, são compostas por várias operações. A ação é o componente principal de algumas atividades e depende das condições em que é dado este fim (Leontiev, 1978b). Uma ação se torna atividade quando o motivo está relacionado com a finalidade proposta.

Nas entrevistas realizadas, quando interrogamos os professores sobre as funções que passaram a executar após o processo de readaptação obtivemos as seguintes respostas: seis auxiliam nos trabalhos da equipe pedagógica; três trabalham na biblioteca; dois realizam trabalhos burocráticos que envolvem controle dos diários, da presença dos professores e impressão de provas; dois auxiliam os alunos com dificuldades no processo de escolarização; dois ajudam a escola de forma geral; dois auxiliam os professores; um trabalha na secretaria; um fotografa e é redatora dos projetos e eventos da escola; e uma afirmou que realiza poucas atividades, sem ter uma função definida.

Analisamos que os professores executam várias ações, mas não atividades - o motivo não tem relação com a ação. No caso da readaptação, isto é muito evidente. Eles auxiliam a escola em vários aspectos, eles desenvolvem várias ações, mas nem sempre relacionada com o significado social da sua profissão, que seria o ensino. Nem sempre há uma intencionalidade de ensinar, porque, de certa forma, não têm mais noção do processo de trabalho. Na sala de aula, com a flexibilização e acirramento das condições de trabalhos isso já era difícil de ocorrer, com o processo de readaptação isso se torna ainda mais complexo.

Uma professora se posiciona de seguinte forma em relação à readaptação:

Eu gostava muito mais de estar na sala de aula, muito mais. E... É, quem está na sala de aula não sabe o quanto é feliz. Porque depois que eu saí da sala eu vi que o lado de fora da sala de aula também não é fácil. Então, feliz é quem está na sala de aula. Mas só passando pela experiência de estar do outro lado é que ele vai valorizar sua sala. Porque ali é seu mundo, você fecha a sua porta, você se realiza, você dá a sua aula... A tua relação com o teu aluno é sua, então assim, é o seu mundo ali. E aqui não, aqui você tá exposta a tudo!... Eu não posso assinar nada porque eu não sou uma pedagoga. Eu não posso participar de determinadas coisas porque eu não sou uma professora. Então, é difícil. (S17)

Leontiev (1978a) afirma que a atividade do sujeito é mediatizada e regulada pela consciência, isto é, pelo reflexo psíquico da realidade. Ela surgiu na passagem da atividade 
adaptativa do animal à atividade produtiva, laboral, que é uma característica específica do homem. No nível da ontogênese, podemos dizer que esse reflexo psíquico da realidade se produz, internamente, a partir da realidade exterior. $E$, para que isso ocorra, a linguagem tem papel fundamental. Neste aspecto Marx e Engels (1996, p. 43) expõem que a linguagem “... é a consciência real, prática, que existe para os outros homens e, portanto, existe também para mim mesmo; e a linguagem nasce, como a consciência, da carência, da necessidade de intercâmbio com outros homens". Embora seja individual, está atrelada às relações sociais.

Para a formação da consciência o sujeito se apropria dos significados. Eles formam a consciência. Nos significados estão presentes as propriedades, as relações, a existência do mundo objetivo, desenvolvidos pela prática social. Esses significados vão sendo apropriados pelo indivíduo, desde o nascimento e dão configuração ao mundo vivenciado. No entanto, Leontiev (1978a, p. 116) afirma que nos significados "... se expressa o movimento da ciência humana e seus recursos cognoscitivos, assim como noções ideológicas da sociedade: religiosas, filosóficas, políticas. Nesta existência objetiva se subordinam as leis histórico-sociais e por sua vez, a lógica interna do próprio desenvolvimento."

No caso do trabalho do professor, objeto de estudo deste artigo, entendemos, a partir de Vigotski (2000) e de Saviani (2003), que sua função é socializar os conhecimentos produzidos pelos homens. É este o significado da escola: ensinar aos alunos os conhecimentos científicos, provocando neles o desenvolvimento das funções psicológicas superiores, tais como a memória, atenção concentrada, abstração, criatividade, entre outras funções. Nove professores entrevistados afirmaram que sentem prazer em dar aula e cinco em ver seus alunos aprendendo, coerente com o significado social da profissão.

Nas relações estabelecidas, a criança se apropria da significação criada pelos homens de forma variada, dependendo do sentido subjetivo que essa significação tenha para ela. Asbahr e Souza (2014) afirmam que "O sentido pessoal expressa a relação subjetiva que o sujeito estabelece com os significados sociais e com as atividades humanas" ( $p$. 170). Nessa relação entre apropriação dos significados e estabelecimento de sentido, constitui-se a personalidade. A personalidade é compreendida por Leontiev (1978a) como uma atividade humana objetivada e vai se constituindo na relação que o indivíduo estabelece com a realidade.

As relações estabelecidas na sociedade são decisivas no plano psicológico, mas o indivíduo atua ativamente neste processo de apropriação dos significados, ele busca satisfazer e desenvolver as necessidades materiais e espirituais, objetivadas e transformadas em motivos de sua atividade. Eles adquirem um sentido pessoal para o sujeito. Esses sentidos "... refletem os motivos engendrados pelas relações vitais reais do homem" (Leontiev, 1978a, p. 121). Quando sentido e significados estão divorciados, ocorre o processo de alienação.

$\mathrm{Na}$ formação da personalidade existem relações hierárquicas das atividades que a caracterizam; algumas atividades se subordinam a outras. Lembramos, conforme Leontiev (1978a), que as atividades são guiadas por motivos, nos quais está objetivada alguma necessidade. Essa hierarquização ocorre em todas as fases do desenvolvimento. Existem, para o autor, "motivos geradores de sentido" e "motivos-estímulos". Aqueles se referem aos motivos que impulsionam a atividade e tem um sentido pessoal; estes impulsionam a ação, mas não dão origem ao sentido. $\mathrm{Na}$ estrutura de uma atividade, certo motivo pode ser gerador de sentido e em outra motivos-estímulos. Porém, os motivos geradores de sentido sempre possuem uma posição hierárquica mais elevada, mas nem sempre se tornam conscientes para o indivíduo. Tal fato pode estar presente na formação da personalidade do professor, que no processo de readaptação, nem sempre toma consciência dos motivos que estão o relacionando com a realidade externa. Pode ocorrer uma transformação no motivo que incita a sua ação de ensinar.

Quando entrevistamos os professores readaptados analisamos que na hierarquização dos motivos, aquilo que movia o professor na escola passa a ocupar uma posição diferenciada: agora o desejo é não estar em sala de aula, o desejo é fugir da situação estressante, por isso, 95\% dos professores dizem gostar do trabalho agora que já não têm que estar mais trabalhando diretamente com o aluno que fica sob suas responsabilidades. O convívio da sala de aula com as dificuldades que as condições de trabalho e a relação com o aluno se apresentavam era muito angustiante para aqueles profissionais que foram readaptados por problemas psíquicos. Não significa, com isso, que estão se desresponsabilizando. Do nosso ponto de vista significa apenas que estão procurando formas de enfrentamento para lidar com as dificuldades que foram surgindo na sala de aula. Eles poderiam simplesmente fazer-de-conta que estavam ensinando, mas ficam angustiados quando veem que não estão cumprindo sua tarefa. O sentido da sua profissão seria levar os alunos a aprenderem, mas quando estão adoecendo não seria este mais o motivo que incita á prática pedagógica. Depois de readaptados, percebemos que também são guiados mais por motivos-estímulos.

Os vínculos vão sendo alterados quando retornam à escola após as várias licenças. Conforme constatamos nas entrevistas, o processo de readaptação ocorreu praticamente da mesma forma em todos os casos: uma sequência de apresentação de atestados médicos, passagem pela perícia do Estado, e, finalmente, readaptação definitiva. Professores relatam que foram muitas idas e vindas ao médico até conseguirem finalizar o processo de readaptação. A maior dificuldade, segundo relato dos professores, ocorre quando há um transtorno psíquico. Nem sempre os peritos tratam com respeito aqueles que estão em sofrimento, como relatam algumas professoras:

Quando a pessoa tem um problema físico, uma doença ou uma deficiência, é mais fácil de provar que você não tem o tato para determinadas coisas... (S1) 
Perícia: Nossa! Muito. A perícia acabou comigo! Eu acho que eu adoeci muito mais tendo que passar pela perícia médica. E todas as perícias são humilhantes! Se você vai doente, você retorna mais doente ainda. (S17)

Embora os professores na totalidade tenham sido acometidos por um problema de saúde física ou psíquica, 17 (85\%) afirmaram que nos últimos 12 meses não tiveram nenhum afastamento por problemas de saúde. A readaptação, portanto, fazendo outras atividades não mais aquelas de ministrar aulas, contribuiu para que se sentissem melhor na escola.

Interrogamos os professores acerca do retorno à escola, depois de várias licenças, na categoria de professor readaptado. Nove entrevistados disseram que foi tranquilo, enquanto que sete relataram que sentiram que os demais professores veem o professor readaptado de uma forma meio pejorativa, há preconceito, discriminação, julgam que ele não trabalha. Quatro professores manifestaram, ainda, desconforto com a situação e dois foram enfáticos em dizer que sofreram muito e outros dois que os demais colegas duvidam da doença deles. Um professor disse que ainda não sabe o que fazer nesta situação, uma vez que não tem uma função específica. Um aspecto que chamou atenção foi o fato de três professores afirmarem que sentem que os colegas têm inveja deles. De forma geral, mesmo aqueles que disseram que foi tranquilo o retorno à escola na categoria de professor readaptado, também em alguns momentos da entrevistas comentaram que nesta posição ele é discriminado, desvalorizado, conforme podemos ver nos depoimentos a seguir:

Você se sente como um... Um... Sabe aquele vaso de flor que a pessoa tem dó de jogar? (S11)

É que eles pensam que o readaptado está morto, entendeu? É uma pessoa que está excluída, praticamente, e não é verdade. (S15)

Porém, com relação aos colegas, tem um certo preconceito. É como se quisessem estar no meu lugar. É como se você não fizesse nada. E não entendem porque que você não pode fazer determinadas coisas. (S17)

Leontiev (1978a) analisa que a situação psicológica real dos sujeitos é construída pelos vários vínculos que ele vai estabelecendo com o entorno social e a consciência do sujeito reflete a hierarquia dos motivos. As relações que os professores estabelecem na atividade profissional interferem na constituição da sua personalidade, vão conformando a sua forma de vivenciar o mundo e a interação com outras pessoas. Não são somente interações sociais: são relações de classes. Nesse aspecto, Vygotsky (1930/2004) e Leontiev (1978a, p. 167) deixam muito claro que o lugar que os indivíduos ocupam nas relações de classes é um componente que vai influenciar na constituição da sua personalidade. A primeira base da personalidade são as riquezas dos vínculos que o indivíduo estabelece com o mundo. Na sociedade capitalista, constatamos que essa riqueza nem sempre é possível. A classe trabalhadora nem sempre consegue ter acessos às produções mais elaboradas.

Fazendo um resumo sobre a personalidade, Leontiev (1978a) diferencia pelos menos três parâmetros básicos da personalidade: a amplitude dos vínculos do homem com o mundo, o nível de hierarquização e sua estrutura geral. Cantarelli (2014, p. 125), a partir do estudo desse autor, comenta: "As relações multifacetadas que o ser humano trava com a realidade são objetivamente contraditórias. Tais contradições geram conflitos que, sob certas circunstâncias, fixam-se e entram na estrutura da personalidade."

No caso dos professores readaptados entrevistados essas contradições estavam presentes em várias situações: sentem prazer em conviver com os alunos, mas em virtude das condições de trabalho e do adoecimento, não conseguem mais ficar em sala de aula. Questionam a forma como o trabalho está organizado, mas querem permanecer na profissão e só se sentem valorizados se forem professores. No entanto, os motivos vão ganhando uma nova hierarquia: não é, em muitas situações, ensinar. É sim poder fazer alguma coisa útil na escola para se sentirem valorizados em uma sociedade que o homem se tornou mercadoria e só vale pelo que produz.

Martins (2001) analisa que as condições objetivas determinam uma prioridade em relação aos motivos-estímulos, muitas vezes na busca da sobrevivência, em detrimento dos motivos-geradores-de-sentido. Nesse aspecto, os professores precisam trabalhar para garantir a sobrevivência material. Os motivos-geradores-de-sentido ficam na idealização, no caso dos professores, no desejo, na fantasia de conseguirem ensinar, fazer aquilo que é esperado socialmente de sua atuação profissional. As condições objetivas não permitem ter motivos geradores de sentido. Ocorre um dualismo: querem ensinar, mas querem, também, estar longe de confronto direto com os alunos. O trabalho deveria emancipar o homem, mas provoca estranhamento.

Nessa linha de raciocínio apresentada por Martins, podemos refletir sobre o processo de adoecimento dos professores readaptados. Zeigarnik (1981) analisa a estrutura dos motivos e as necessidades para entender a patopsicologia². Ela afirma:

Podemos falar de uma modificação patológica da personalidade quando sob a influencia da enfermidade diminuem os interesses da pessoa, suas necessidades, quando permanece indiferente ante coisas que antes the inquietavam, quando seus atos não têm objetivo, as ações não são meditadas, quando a pessoa deixa de regular seu comportamento, não pode valorizar adequadamente suas capacidades, quando se modifica sua atitude consigo mesmo e com o mundo que a rodeia. Esta atitude modificada é indicador da mudança da personalidade. (Zeigarnik, 1981, p. 29).

2 Na década de 1920, autores soviéticos começaram a desenvolver estudos relacionados à psicopatologia com base em uma psicologia marxista-leninista, chamados na União Soviética de Patopsicologia. Zeigarnik desenvolveu a Patopsicologia Experimental, sob os princípios do materialismo histórico e dialético (Silva \& Tuleski, 2015). 
Quando o indivíduo está enfermo, segundo a autora, ocorre modificação em sua estrutura motivacional, altera-se a hierarquização estabelecida, seus pontos de vista, seus valores. Os professores entrevistados estão adoecidos. O transtorno psíquico foi o diagnóstico mais recebido para justificar o processo de readaptação: depressão $(n=08)$, síndrome do pânico (1), síndrome do pânico e depressão $(n=3)$. Além disso, outros problemas orgânicos também levaram ao processo de readaptação, tais como: problemas nas cordas vocais $(n=3)$, diabetes $(n=2)$, problemas musculares $(n=3)$; ortopédicos $(n=2)$. Um dos entrevistados teve leucemia e outro câncer de pele.

Zeigarnik (1981) compreende que o adoecimento não é decorrente somente da estrutura da personalidade do indivíduo ou que qualquer forma de atividade decorre diretamente do cérebro, do aspecto biológico. Ela analisa que as anomalias da atividade pessoal e cognitiva percorrem um longo caminho de formação durante toda a vida, "... no qual se entrelaçam a percepção das propriedades e relações naturais dos objetos e fenômenos com as experiências coletivas e as normas sociais" (Zeigarnik, 1981, p. 201). As doenças que acometeram o professor, portanto, mesmo aquelas de cunho orgânico, também estão entrelaçadas com os sentidos que foram dando ao trabalho.

Desta forma, compreender o adoecimento do professor demanda, além de conhecer como está estruturada a sua personalidade, analisar o contexto em que este adoecimento ocorre, e no caso desta pesquisa, estamos dando um enfoque nas relações de trabalho às quais o professor readaptado está submetido. Tem que se fazer uma análise qualitativa das distintas formas de desintegração da psique, levando em conta os mecanismos de atividades alteradas e as possibilidades de sua recuperação.

\section{Considerações Finais}

Como mencionamos na introdução deste artigo, os dados obtidos nas entrevistas com os professores foram utilizados para exemplificar questões teóricas acerca do adoecimento e as relações de trabalho. Não foi nossa intenção nos determos nas respostas dos professores, mas sim enriquecer a discussão teórica.

Conforme vimos no decorrer do artigo, as condições de trabalho têm levado muitos professores ao adoecimento, acompanhado de sofrimento. Os dados da pesquisa realizada com os professores readaptados e a literatura que trata do tema explicitaram esse aspecto. Como Marx (2008) trata do estranhamento, podemos compreender que o professor não se sente em casa no trabalho. Não é nesse espaço que ele vai se constituir como gênero humano. Mas é melhor ficar distante daquela cobrança de ensinar, de ser responsável pelos alunos, mesmo que isso implique em preconceito por parte dos colegas de trabalho. O adoecer seria uma forma de proteção quanto à exposição diária às condições precárias de ensino. Ouvimos em relato de professores que o que gostam na escola é de ensinar, de estar com os alunos. O trabalho, conforme a psicologia histórico-cultural, é a forma de relação que o adulto estabelece com o mundo, mas é um trabalho que não se constitui em atividade para quase todos os professores entrevistados.

Zeigarnik (1981) afirma que é importante conhecer não somente o que está debilitado. Seguindo o que propõe Vigotski (2000), temos que analisar o que se encontra no nível do desenvolvimento real e do proximal, o que está intacto e o que está debilitado no psiquismo e, no caso do professor, constatar as suas potencialidades para continuar a desenvolver sua atividade de ensino.

As relações de trabalho estão complexas com a flexibilização, terceirização, perda de conquistas trabalhistas, e o professor vive isso cotidianamente. No caso do Estado do Paraná, onde realizamos as entrevistas, essa classe profissional vem sofrendo todo tipo de violência, tanto a psíquica quanto a física; basta lembrar o massacre que ocorreu em abril de 2015 no período de greve quando policiais avançaram em direção aos professores como se estes fossem bandidos, num confronto corpo a corpo, deixando professores machucados, com marcas no corpo e no psiquismo.

Do nosso entendimento, o adoecimento, em muitas situações, é forma de resistência à precariedade do trabalho, embora na entrevista os professores, mesmo mencionando essa precariedade, não demonstraram tomar consciência do fato de forma mais aprofundada. Sentem-se adoecidos, sofrem, mas ainda pensam que a culpa é deles. Sentem vergonha, choram quando falam da situação, principalmente no caso dos transtornos psíquicos, que são os mais difíceis de serem compreendidos pelos demais professores e mesmo por especialistas, no caso das perícias. Sentimentos contraditórios permeiam a atividade profissional desses professores.

O sofrimento acaba sendo individualizado neste ou naquele professor, mas é necessário coletivamente fazer esse enfrentamento. Antunes e Praun (2015, pp. 423-424) apostam na solidariedade, no sentido do pertencimento de classe, conjugando ações, como formas de “... ser efetivamente capazes de demolir o sistema de metabolismo social do capital e sua lógica destrutiva e, desse modo, capazes de começar a desenhar um novo modo de vida".

Entendemos que cabe à escola a emancipação dos alunos, a humanização no sentido de apropriação dos bens culturais desenvolvidos no processo histórico, no entanto, o processo de alienação permeia a relação professor-aluno-conhecimento. As condições de trabalho e mesmo a falta de tomada de consciência, muitas vezes, dessas condições e de formas de enfrentamento, produzem adoecimento no professor. Condições objetivas e subjetivas conduzem o professor a essa situação. Ele lida com a finalidade de produzir no aluno aquilo que a humanidade já produziu, conforme apregoa Saviani (2003), mas não tem os elementos necessários no trabalho precarizado para realizar a sua tarefa. Com a alienação, ele se tornou somente uma mercadoria. Vende sua força de trabalho, e o produto de seu trabalho o conhecimento - também nem sempre é apropriado pelo aluno, e nesta cadeia de ações que executa, não encontra um motivo-gerador-de-sentido, executa somente ações. 
Isso, no entanto, não ocorre na esfera do particular. Como afirma Leontiev (1978b, p. 274), a desigualdade entre os homens é "... produto da desigualdade econômica, da desigualdade de classes e da diversidade consecutiva das suas relações com as aquisições que encarnam todas as aptidões e faculdades da natureza humana, formadas no decurso de um processo sócio-histórico." Como afirmavam Marx (2008) e Leontiev (1978a), o prazer e o trabalho estão divorciados. Falar da alienação não é fator secundário na análise da temática deste artigo. $\mathrm{O}$ adoecimento do professor tem que ser compreendido na sua totalidade, observando as contradições presentes na sociedade e na forma como o profissional lida com a labuta do dia a dia na escola.

Entendemos que a pesquisa que realizamos com os professores readaptados teve algumas limitações, entre elas o fato de lidar com aqueles que já têm um diagnóstico. Outros estudos ainda se fazem necessários, compreendendo o adoecimento para além da esfera individual, pois muitas vezes é este o caminho encontrado para explicar porque o professor adoece e é submetido ao processo de readaptação.

\section{Referências}

Antunes, R. (2002). Os exercícios da subjetividade: as reificações inocentes e as reificações estranhadas. Caderno $\mathrm{CRH}, 37,119-$ 129.

Antunes, R. (2006). Os sentidos do trabalho. Ensaios sobre a afirmação e a negação do trabalho. São Paulo: Boitempo.

Antunes, R. (2009). Os sentidos do trabalho. Ensaios sobre a afirmação e a negação do trabalho (2a. ed.). São Paulo: Boitempo.

Antunes, R. (2011). Adeus ao trabalho: ensaio sobre as metamorfoses e a centralidade do mundo do trabalho (15a ed.). São Paulo: Cortez; Campinas: Editora da Universidade Estadual de Campinas.

Antunes, R.; Praun, L. (2015). A sociedade dos adoecimentos no trabalho. Serviço Social, 123, 407-427.

Antunes, S. M. P. S. N. (2014). Readaptação e identidade docente: um relato de pesquisa. Cadernos de Educação, 13(26), 149-158.

Asbahr, F.S.F.; Souza, M.P.R. (2014). "Por que aprender isso, professora?" Sentido pessoal e atividade de estudo na Psicologia Histórico-Cultural. Estudos de Psicologia, 19(3), 157-238.

Assunção, A. A.; Oliveira, D. (2009). A. Intensificação do trabalho e saúde dos professores. Educação e Sociedade, 30(107), 349-372.

Cantarelli, A. G. (2014). A subjetividade como intersubjetividade: a personalidade do professor e as suas relações com a prática docente. Dissertação de Mestrado, Universidade Estadual de Maringá, Maringá, PR.

Gasparini, S. M.; Barreto, S. M.; Assunção, A. A. (2005). O professor, as condições de trabalho e os efeitos sobre sua saúde. Educação e Pesquisa, 31(2),189-199.

Heloani, J. R. (2003). Gestão e organização no capitalismo globalizado: história da manipulação psicológica no mundo do trabalho. São Paulo.

Heloani, J. R.; Capitão, C. G. (2003). Saúde mental e psicologia do trabalho. Em Perspectiva, 17(2), 102-108.

Hirata, H. (2002). Tendências recentes da precarização social e do trabalho: Brasil, França, Japão. Caderno CRH, 37, 13-20.

Instrução normativa n. 02/2007 - GRHS/SEED (2007). Curitiba: Secretaria de Estado da Educação, Grupo de Recursos Humanos Setorial. Recuperado: 20 ago. 2016. Disponível: http://www.educacao.pr.gov.br/arquivos/File/instrucoes/ instrucao022007grhsseed.pdf.

Lei n. 6174/70 de 16 de novembro de 1970 (1970, 16 de novembro). Estabelece o regime Jurídico dos funcionários civis do Poder Executivo do Estado do Paraná. Paraná: Estatuto do Servidor Funcionários Civis do Paraná. Recuperado: 20 ago. 2016. Disponível: http://www.portaldoservidor.pr.gov.br/arquivos/File/ estatutoservidor.pdf.

Lessa, S. (2012). Mundo dos homens: trabalho e ser social (3a. ed.). São Paulo: Instituto Lukács.

Leontiev, A. N. (1969). Las necesidades y los motivos de la atividade. In: Smirnov, A.; Leontiev, A.N.; Rubisthein, S.; Tieplov, B. M. (Orgs.), Psicologia (pp. 341-352).México: Grijalbo.

Leontiev, A. N. (1978a). Actividad, conciencia e personalidad. Buenos Aires: Ciencias del Hombre.

Leontiev, A. N. (1978b). Desenvolvimento do psiquismo. Portugal: Horizonte,

Markus, G. (2015). Marxismo e antropologia: o conceito de essência humana na filosofia de Marx. São Paulo: Expressão Popular.

Martins, L. M. (2001). Análise sócio-histórica do processo de personalização de professores. Tese de Doutorado em Educação, Universidade Estadual Paulista, Marília, SP.

Martins, L. M.; Eidt, N. M. (2010). Trabalho e atividade: categorias de análise na psicologia histórico-cultural do desenvolvimento. Psicologia em Estudo, 15(4), 675-683.

Marx, K. (1988). O capital: crítica a economia política (R. Sant'Anna, Trad.). Rio de Janeiro: Bertrand Brasil.

Marx, K. (2008). Manuscritos econômico-filosóficos. São Paulo: Boitempo.

Marx, K.; Engels, F. (1996).A ideologia alemã (10a. ed.). São Paulo: 
Editora Hucitec.

Netto, N. B.; Carvalho, B. P. (2015). Trabalho, universidade e suicídio: uma análise da precarização/intensificação do trabalho docente desde o materialismo histórico-dialético. Revista Advir/Associação dos Docentes da Universidade do Estado do Rio de Janeiro, 33, 67-85.

Sampaio, M. M. F.; Marin, A. J. (2004). Precarização do trabalho docente e seus efeitos sobre as práticas curriculares. Educação e Sociedade, 25 (89), 1203-1225.

Saviani, D. (2003). Pedagogia histórico-crítica: primeiras aproximações (8a. ed.). Campinas: Autores Associados.

Silva, F. G. (2011). O professor e a educação: entre o prazer, o sofrimento e o adoecimento.Revista Espaço Acadêmico, 124, 5766.
Silva, M. A. S.; Tuleski, S. C. (2015). Patopsicología experimental: enfoque histórico-cultural para entender o sofrimento mental. Estudos de Psicologia, 20(4), 207-216.

Tumolo, P. S.; Fontana, K. B. (2008). Trabalho docente e capitalismo: um estudo crítico da produção acadêmica da década de 1990. Educação e Sociedade, 29(102), 159-180.

Vigotski, L. S. (2000). A construção do pensamento e da linguagem (P. Bezerra, Trad.). São Paulo: Martins Fontes.

Vygotsky, L. S. (2004). A transformação socialista do homem. (Dória, N., Trad.). Marxists Internet Archive. (Trabalho original publicado em 1930). Recuperado: 1 fev. 2007. Disponível: http//:www. marxistts.org/.

Zeigarnik. B. V. (1981). Psicopatologia. Madri: Akal Editor.

Recebido em: 22 de fevereiro de 2017 Aceito em: 10 de maio de 2017

Agradecemos o apoio da CAPES pelo apoio financeiro à pesquisa realizada por meio da Bolsa PNPD e ao CNPq por meio da bolsa de produtividade em pesquisa. unrestricted use,distribution and reproduction in any medium, provided the original article is properly cited. 